\title{
ASPECTOS DAS PRÁTICAS DE AGRICULTURA URBANA EM CATALÃO-GO
}

\author{
Aspects of urban agriculture practices in Catalão-GO
}

Aspectos de las prácticas de agricultura urbana en Catalão-GO

\author{
Claudio Jose Bertazzo * \\ Guilherme Papini da Silva ** \\ Gabriela Ferreira de Souza *** \\ * Universidade Federal de Catalão (UFCAT) - cbertazzo@gmail.com \\ ** Universidade Federal de Goiás (UFG) - milleniun10@hotmail.com \\ *** Universidade Federal de São Carlos (UFSCar) - gabygaia.bio@hotmail.com
}

Recebido em 02/12/2020. Aceito para publicação em 05/03/2021.

Versão online publicada em 23/03/2021 (http://seer.ufrgs.br/paraonde)

Como citar este artigo: BERTAZZO, C. J. SILVA, G. P da. SOUZA, G. F de. Aspectos das práticas de agricutura urbana em Catalão-GO. Para Onde!?, v. 15, n. 1, p. 16-34, 2021.

\section{Resumo:}

Para conhecer, analisar e dar visibilidade à Agricultura Urbana (AU) na cidade de Catalão (GO), Brasil, estabeleceu-se uma pesquisa teórico-prática no âmbito de um projeto de extensão financiado pelo Programa de Extensão financiado pelo MEC/SESu. Assim, procurou-se trazer a teoria para dentro da realidade local, juntando ambas as esferas para observar as experiências dessa modalidade agrícola na cidade. $O$ objetivo da investigação consistiu em identificar as particularidades da $\mathrm{AU}$ e quantificar 'o que', 'como' e 'para que' estava a ser produzido, procurando construir o entendimento de seu estágio, e, então, demonstrar, ou não, a importância da AU como alternativa para se ter uma cidade com maior segurança e autonomia alimentares. Os procedimentos metodológicos consistiram, além da revisão bibliográfica, nas visitas a campo para proceder às enquetes e conhecer as modalidades de agricultura na cidade de Catalão (GO). Na presente reflexão, demonstra-se, por meio da amostra territorial e dos domicílios pesquisados, que a AU é real. Ela já é e tem potencial para se tornar amplamente uma oportunidade de acesso a alimentos seguros e nutritivos a todos os citadinos que possuem quintais ou pequenos espaços para cultivo em seus domicílios. Os resultados da pesquisa permitiram identificar e classificar o que produzem e o destino da produção. Concluiuse que a Agricultura Urbana é real e disseminada no território, podendo ser, ou não, herança cultural de antigos agricultores radicados na cidade. Entretanto, há muito para evoluir e ocupar melhor os espaços domiciliares.

Palavras-chave: quintais produtivos; segurança alimentar; agricultura sustentável

\begin{abstract}
:
In order to know, analyze and give visibility to Urban Agriculture (AU) in the city of Catalão (GO), Brazil, a theoretical-practical research was established within the scope of an extension project financed by the Extension Program financed by MEC / SESu. Thus, we tried to bring the theory into the local reality, joining both spheres to observe the experiences of this agricultural modality in the city. The objective of the investigation was to identify the particularities of the AU and quantify 'what', 'how' and
\end{abstract}


'what' was being produced, seeking to build the understanding of its stage, and then demonstrate, or not, the importance AU as an alternative to have a city with greater food security and autonomy. The methodological procedures consisted, in addition to the bibliographic review, in the field visits to carry out the surveys and to know the agricultural modalities in the city of Catalão (GO). In this reflection, it is demonstrated, through the territorial sample and the households surveyed, that the AU is real. It already is and has the potential to become widely an opportunity for access to safe and nutritious food for all city dwellers who have backyards or small spaces for cultivation in their homes. The research results allowed to identify and classify what they produce and the destination of the production. It was concluded that Urban Agriculture is real and disseminated in the territory, which may or may not be the cultural heritage of former farmers living in the city. However, there is much to evolve and better occupy home spaces.

Keywords: productive backyards; food security; Sustainable Agriculture

\begin{abstract}
Resumen
Con el fin de conocer, analizar y dar visibilidad a la Agricultura Urbana (UA) en la ciudad de Catalão (GO), Brasil, se estableció una investigación teórico-práctica en el marco de un proyecto de extensión financiado por el Programa de Extensión financiado por MEC / SESu. Así, intentamos llevar la teoría a la realidad local, uniendo ambos ámbitos para observar las vivencias de esta modalidad agrícola en la ciudad. El objetivo de la investigación fue identificar las particularidades de la UA y cuantificar 'qué', 'cómo' y 'qué' se estaba produciendo, buscando construir el entendimiento de su desarrollo, y luego demostrar, o no, la importancia de la UA como alternativa para tener una ciudad con mayor seguridad y autonomía alimentaria. Los procedimientos metodológicos consistieron, además de la revisión bibliográfica, en las visitas de campo para realizar las encuestas y conocer las modalidades agrícolas en la ciudad de Catalão (GO). En esta reflexión, se demuestra, a través de la muestra territorial y los hogares encuestados, que la UA es real. Ya es y tiene el potencial de convertirse ampliamente en una oportunidad de acceso a alimentos seguros y nutritivos para todos los habitantes de la ciudad que tienen patios traseros o pequeños espacios para cultivar en sus hogares. Los resultados de la investigación permitieron identificar y clasificar lo que producen y el destino de la producción. Se concluyó que la Agricultura Urbana es real y está diseminada en el territorio, que puede ser o no patrimonio cultural de los antiguos agricultores, hoy residentes en la ciudad. Sin embargo, queda mucho por evolucionar y ocupar mejor los espacios del hogar.
\end{abstract}

Palabras clave: patios interiores productivos; seguridad alimentaria; Agricultura sostenible

\title{
1. Introdução
}

A proposta da pesquisa que deu origem a este artigo emergiu da necessidade de se conhecer, analisar e dar visibilidade à Agricultura Urbana (AU) na cidade de Catalão (GO) no âmbito de um projeto de extensão financiado pelo Ministério da Educação, por meio do Programa de Extensão Universitária (PROEXT) MEC/SESU. A pesquisa e o artigo foram movidos pelo objetivo de construir conhecimento sobre a $\mathrm{AU}$ em Catalão (GO), sendo, portanto, uma etapa de um grande programa de extensão relacionado à Agroecologia em suas dimensões como ciência, prática agrícola e como movimento.

Para que pesquisar a Agricultura Urbana em Catalão (GO)? Em primeiro lugar, para conhecer uma realidade e identificar perfis e características de sua população. Se cultivam, ou não, seus quintais, 'por que', 'o que' e 'para que' os cultivam. Em 
segundo lugar, foi muito motivadora a dúvida que emerge ao se reconhecer que há agricultura nas residências urbanas: o que essas pessoas fazem com o que colhem? $\mathrm{E}$, se realmente os colhem, a que se destina a colheita? Para tais perguntas, encontraram-se muitas respostas.

Também esteve sempre presente a dúvida instigante sobre as razões que levam os citadinos a cultivarem seus quintais. Seria por causa da cultura agrícola? Da cultura do uso dos fitoterápicos? Do lazer? Dos modos saudáveis de exercícios corporais? Muitos motivos, excelentes razões. E por necessidade? Não exatamente pela fome, mas pelo prazer de comer saudavelmente as coisas de que gostam de comer. Necessidade de saber que têm à mão certos itens de alimentação ligados à cultura e à ancestralidade? $\mathrm{E}$, nesse caso, seriam os guardiães de sementes, de variedades e de espécies locais? Os resultados do artigo indicarão as respostas.

Considerando que as sociedades e os governos sempre se preocuparam com a segurança alimentar de seus nacionais e demais habitantes do território, as famílias, de certa forma, também se preocupam e se organizam para que não tenham falta de comida ou sofram carências de determinados nutrientes que só se encontram em alguns produtos naturais. Por conseguinte, como ensinam as ciências da nutrição, a questão alimentar vai bem além de seus aspectos quantitativos e numéricos calóricos: é também necessário conhecer a qualidade e a segurança nutricional dos alimentos. E por quê? Porque a questão 'segurança alimentar' é recorrente em todas as épocas. Essa expressão até pode parecer um conceito de construção e uso recentes, talvez reformulado. Contudo, as circunstâncias de fome e de fome oculta (subnutrição) vêm sempre acompanhadas da problemática da qualidade dos alimentos. Elas são as responsáveis pela imersão do conceito de "segurança nutricional" ou de "alimentos seguros e nutritivos". Esses são conceitos indispensáveis para a saúde humana. O artigo, certamente, acompanha as considerações e os conceitos, como o de "segurança alimentar e nutricional", propostos pelo Conselho Nacional de Segurança Alimentar e Nutricional (CONSEA), o qual os expressa como sendo o direito de todos a ter uma alimentação saudável, acessível, qualitativa, suficiente e permanente. Tal conceito foi acolhido pelo legislativo brasileiro ao promulgar a Lei 11.346, de 15 de setembro de 2006, pela qual foi criado o Sistema Nacional de Segurança Alimentar e Nutricional (SISAN). Conforme o texto da lei em comento, ficaram definidos e estabelecidos alguns conceitos, como o de segurança alimentar e nutricional, como se pode ler no Art. $3^{\circ}$ :

\begin{abstract}
A segurança alimentar e nutricional consiste na realização do direito de todos ao acesso regular e permanente a alimentos de qualidade, em quantidade suficiente, sem comprometer o acesso a outras necessidades essenciais, tendo como base práticas alimentares promotoras de saúde que respeitem a diversidade cultural e que sejam ambiental, cultural, econômica e socialmente sustentáveis. (BRASIL, 2006, Art. 3ํ)
\end{abstract}

Portanto, por meio desse conceito introduzido pela Lei 11.346/2006 é que se passa a afirmar que a Agricultura Urbana (AU) oportuniza o acesso à segurança alimentar e nutricional, ressaltando que ela tem função de promover direito à alimentação segura, saudável, suficiente e permanente. Entretanto, as populações em situação de vulnerabilidade ou não, precisam ser ensinadas e motivadas a iniciarem suas hortas domésticas, sem se importar com o tamanho ou dimensão que 
possam ter.

De certa forma, pode-se afirmar que, a partir do conceito de segurança alimentar e nutricional, surge, como contraponto, a concepção de soberania alimentar. Sabe-se que a soberania alimentar sintetiza os direitos de se ter alimentos nas quantidades e nas qualidades em que se deseje tê-los. O que se compreende, então, é que segundo o conceito de soberania alimentar, não se trata apenas de ter alimentos nutritivos e permanentes, mas ter os mantimentos que se queira comer no momento, na quantidade e na qualidade que se almeje. Assim, a "soberania alimentar" é mais ampla que a segurança alimentar, de modo que, na primeira, cada sujeito pode escolher a sua própria comida: “como', 'quando' e 'quanto' quiser, podendo escolher 'onde' e 'de quem' quer comprar, quando na posição de consumidor.

Nessa mesma direção, a organização Centro Ecológico - Núcleo Litoral Norte - em seu Boletim Informativo sobre 'Soberania Alimentar', de outubro de 2008, entende que 0

[...] conceito de soberania alimentar foi inicialmente postulado pela Via Campesina e pode ser enunciado como 'o direito dos povos a alimentos nutritivos e culturalmente adequados, acessíveis, produzidos de forma sustentável e ecológica, e o direito de decidir seu próprio sistema alimentar e produtivo'. Apesar deste direito ser incontestável e exigível, o modelo de desenvolvimento adotado de maneira hegemônica pouco tem colaborado para seu alcance. (BOLETIM CENTRO ECOLÓGICO - NÚCLEO LITORAL, Vol. 1, Ed 12008, p. 1)

Aqui, fica aclarada a situação de dominação dos impérios alimentares e justificada por que a AU desponta como uma alternativa para o exercício dessa soberania alimentar.

Neste trabalho, todavia, se evitará o exame mais aprofundado desses conceitos para abordar, conhecer e quantificar, ainda que amostralmente, a produção de comida na cidade pelos próprios citadinos para autoconsumo ou para as destinações que informarem.

A fim de sequenciar e sistematizar as informações, este trabalho está organizado por seções, procurando expor, de modo expressivo e claro, a pesquisa e os procedimentos metodológicos que a orientaram. Posteriormente, serão discutidos os resultados da pesquisa e as conclusões a que se chegou, com base na leitura da realidade e no apoio teórico proporcionado por autores como Nogaard (1987), Altieri e Nicholls, (2000), Machado e Machado (2002), Brustolin et al. (2003), Muniz (2003), Costa Gomes (2005) e Ferreira e Castilho (2007).

\section{As rotas da pesquisa}

Tendo sido contemplado com financiamento para a execução de um projeto de extensão, cujo ente financiador foi o Ministério da Educação, por meio do Programa de Extensão Universitária (PROEXT) - MEC/SESu, colocou-se em curso as etapas do projeto de extensão sendo uma delas a realização para a pesquisa sobre as ocorrências e práticas da Agricultura Urbana (AU) na cidade de Catalão (GO). A partir da obtenção das informações sobre as práticas de AU passou-se para a organizar as demais etapas do projeto de extensão financiado pelo PROEXT. 
Por suposto, parte das pesquisas empreendidas no projeto se encontram dentro dos conceitos de pesquisas descritiva e explicativa (GIL, 2009), de modo que procurou-se conhecer, analisar, classificar, descrever e, também, explicar os fenômenos pesquisados. Os resultados das coletas de dados compuseram o cenário para a análise e tomada de decisão das etapas posteriores do projeto, notadamente a oferta de oficinas e formações em Agroecologias e práticas agroecológicas.

Os procedimentos metodológicos que movimentaram o projeto e que proporcionaram a produção de informações, inclusive as que se encontram registradas nesse artigo, aconteceram em três etapas distintas:

i) Por conter uma pesquisa empírica, e não somente ela, o projeto delineou, primeiramente, uma revisão da bibliografia sobre agricultura urbana e periurbana e do exame da documentação nacional produzida nas Secretarias dos Ministérios que tutelam as questões da pobreza e da agricultura urbana. Estas leituras colaboraram, ainda que tenuemente, para a elaboração do formulário de enquete/questionário sobre práticas de agricultura nas residências urbanas.

ii) A enquete, portanto, foi a segunda etapa da pesquisa, definida como pesquisa empírica cujos resultados produziram quadros, tabelas e gráficos. Nessa fase de trabalho de campo, tomou-se as informações conforme os sujeitos as declaravam. Não houve, obrigatoriamente, observações de campo. Por que? Porque nem todos os domicílios abriram suas portas para os pesquisadores. Quando foram convidados a entrar, os pesquisadores fotografaram os cultivos e criações existentes mediante anuência verbal dos residentes. $O$ atendimento nos domicílios foi efetuado pelos pais ou pelas mães, conforme estivessem presentes no momento da pesquisa. Esse foi o procedimento padrão: entrar no domicílio para pesquisar o quintal somente em presença dos chefes de família.

iii) Além destas duas primeiras etapas, promoveu-se, como terceira etapa, atividades de formação e intervenções dialógicas com ênfase nas aprendizagens sociopráticas, que proporcionaram uma dimensão de extensão ao projeto. Embora houvesse um programa de cursos, este era, de certa forma, aberto para poder acolher algumas demandas dos participantes. Nessas formações, debateu-se as questões culturais e identitárias da agricultura e suas modalidades, com legado da ancestralidade e da herança cultural dos participantes.

O levantamento consistiu na técnica de pesquisa (GIL, 2009) escolhida para a parte empírica/observação de campo. Ele foi precedido pelo desenvolvimento de uma ficha de levantamento/observação adequada aos objetivos da pesquisa. Após analisarem-se outras pesquisas com objeto similar, elaborou-se uma enquete própria que permitisse obter informações necessárias que respondessem às perguntas sobre a existência de práticas de Agricultura Urbana e, 'como' e 'quais' espécies eram cultivadas. O conjunto de informações coletadas também foram usadas para organizar o trabalho de educação agroecológica, o qual foi levado a cabo na terceira fase dos trabalhos. Evidentemente, foi após o encerramento da pesquisa empírica que se passou à etapa de planejamento de cursos e de oficinas com foco em hortas urbanas e na produção agroecológica nas cidades. Os cursos foram desenhados de modo a preencher algumas lacunas observadas na pesquisa empírica, como por exemplo: manejo de plantas, elaboração de insumos, preparação de compostagens e etc. 
O instrumento da enquete proporcionou coletar informações das quantidades e variedades de espécies cultivadas nos quintais do território amostral; também permitiu registrar formas de manejo e características particulares identificadas nos domicílios do território em estudo, quando foi possível adentrar nos quintais. As fichas foram preenchidas nos domicílios durantes as enquetes de 2013 e 2019, segundo as declarações dos moradores/responsáveis pelas informações. No ano de 2019, enfatizou-se as pesquisas domiciliares em alguns bairros, pelo fato de serem bairros periféricos da cidade, localizados no limite periurbano e pelas características verificadas na primeira edição da pesquisa.

Considerando ser impossível a realização censitária em toda a planta urbana, foi decido que seria feita uma coleta amostral. Os critérios da amostra não resultaram de nenhuma base estatística. Foi uma formulação própria, baseada nas condições que se dispunha para realizar a pesquisa. Numa reunião com pesquisadores, surgiu a ideia de escolher, por meio de imagens aéreas ou de satélites, um setor da cidade que indicasse a presença de quintais com vegetação. Isso seria observável pela reflectância, albedo, absorção da luz, superfícies rugosas e dosséis de plantas. Resolvida a questão dos critérios para definir a amostra, buscou-se as imagens disponíveis e aplicou-se os critérios eleitos. Os setores escolhidos foram aqueles que, na imagem do satélite, mostraram maior quantidade de áreas verdes ou áreas abertas, que aparentavam possuir potencialidade para a produção de alimentos.

Foi, então, selecionado um recorte amostral da cidade que pudesse representar a sua totalidade e que pudesse apresentar possíveis práticas de Agricultura Urbana. Foi selecionada a área em uma imagem de satélite disponível no Programa Google Earth. Analisada a imagem da cidade, escolheu-se a região nordeste de Catalão, mais precisamente a área delimitada à norte da Avenida Dr. Lamartine Pinto de Avelar e a leste da Avenida JK. Área que engloba os bairros, Ipanema, Leblon, Bairro das Américas, Vila Chaud, Cruzeiro I e II e Evelina Nour I e II.

No Croquis 1, elaborado por meio de imagem do Google Earth, é possível observar que há uma área marcada em vermelho, correspondente ao quadrante que representa a região Nordeste de Catalão: área utilizada para a pesquisa de campo. Nessa área, demarcaram-se, em amarelo, os setores nos quais foram aplicadas as enquetes que forneceram a base empírica para este artigo. As áreas 1 e 2 abrigam as duas hortas comerciais localizadas nos bairros Ipanema e Leblon, cujas imagens estão registradas nas Fotos $n .01$ e $n .{ }^{\circ}$. As áreas de 3 a 10 correspondem a quarteirões escolhidos dentro de cada bairro. São as seguintes áreas: 3) Ipanema, 4) Vila Chaud, 5) Leblon, 6) Bairro das Américas, 7) Cruzeiro I, 8) Cruzeiro II, 9) Evelina Nour I e 10) Evelina Nour II.

Em cada uma dessas áreas, foram pesquisados oito domicílios. Primeiramente, fazia-se o perímetro de cada área e contavam-se as casas, para então decidir pelo salto randômico para as pesquisas, de modo que cada área teria exatamente oito domicílios pesquisados. Obtinha-se o resultado saltando de duas em duas casas, de três em três casas ou de quatro em quatro casas, conforme o número que era encontrado em cada área (Croquis 1). 


\section{CROQUIS 1: Setor da planta urbana de Catalão delimitado para a pesquisa}

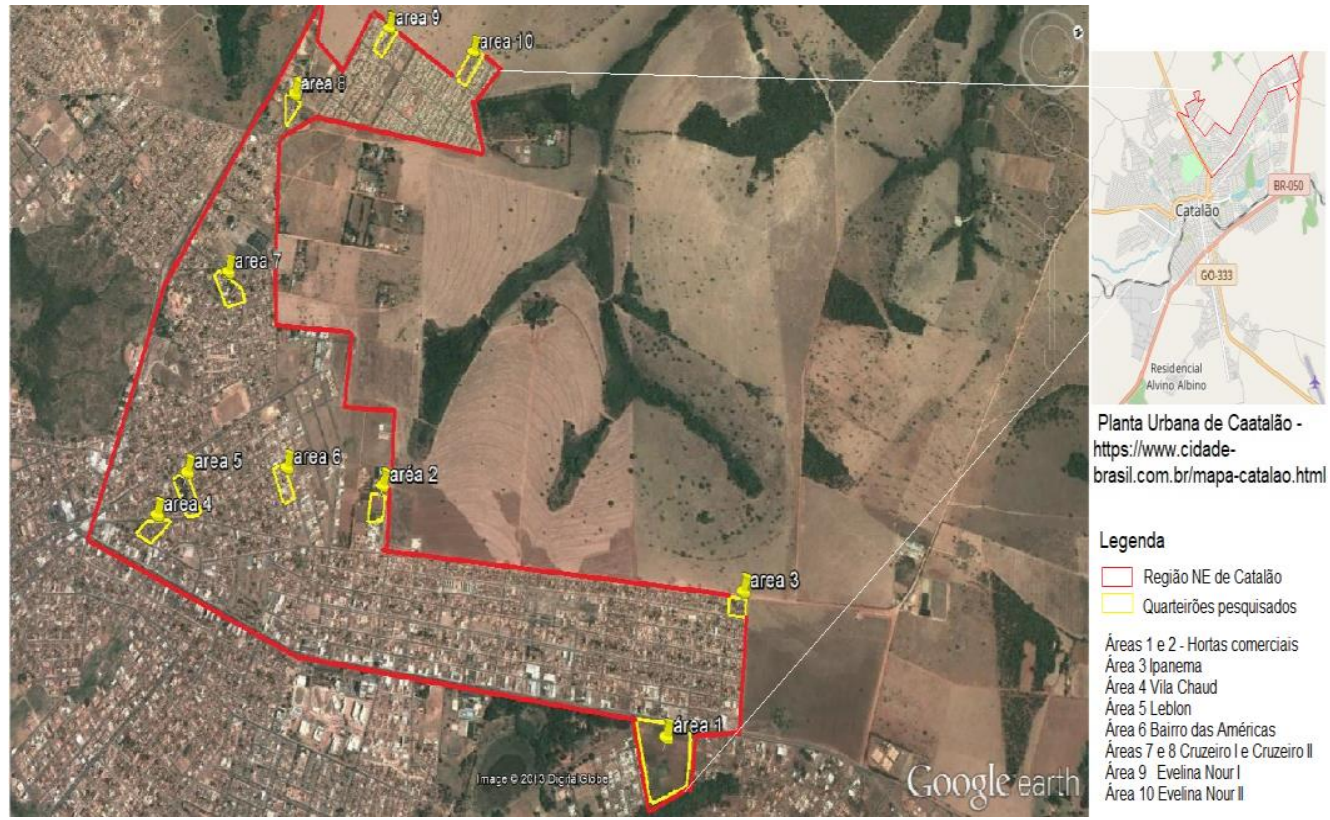

Fonte: Google Earth. organozado pelo autores 2013/

A áreas de amostragem estão demarcadas com linha amarela no Croquis 1 , dentro do recorte da região nordeste de Catalão (GO), demarcada, por sua vez, com linha vermelha. Seguindo essa metodologia de 8 domicílios em cada uma das oito áreas, chegou-se a 64 domicílios pesquisados. Nas áreas 1 e 2, foram pesquisadas as duas hortas comerciais, chegando-se a 66 unidades de Agricultura Urbana pesquisada. $O$ total de domicílios que integram essas oito áreas residenciais é de 240. Separou-se, a partir da identificação na imagem do satélite (Croquis 1), os setores identificados com semelhança (aparência) de hortas comerciais,

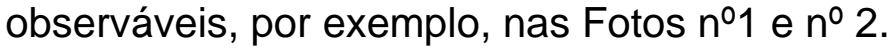

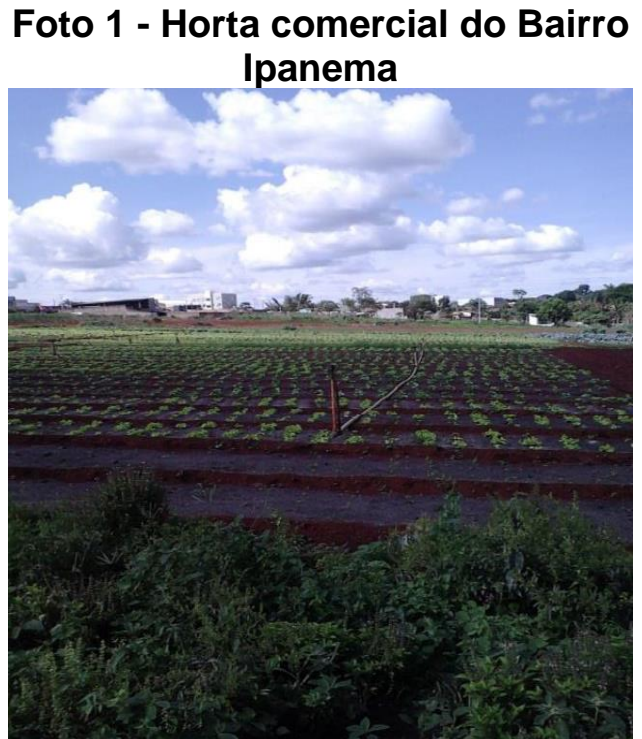

Fonte: Pesquisa de Campo 2013/2019

\section{Foto 2 - Horta comercial do Bairro Leblon}

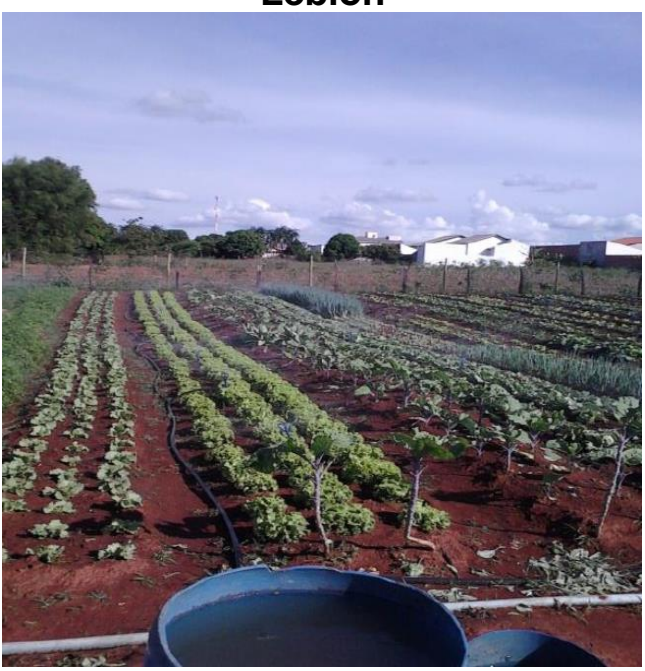

Fonte: Pesquisa de Campo 2013/2019 


\section{Fome, "políticas públicas" e Agricultura Urbana}

A pobreza e a fome das populações urbanas, como se lê e ouve nas mídias, são as mesmas que se observam na vida. Conquanto existam ações da sociedade civil organizada e das "políticas públicas" para o enfrentamento da fome, esta permanece em suas duas formas mais agressivas: a fome propriamente dita e a fome oculta, que é a subnutrição. Todavia, é possível, por meio de ações pontuais, estimular ações que visem apoiar as famílias a fim de motivá-las a adquirir hábitos de cultivar em hortas próprias ou comunitárias. No caso de assentamentos precários e invasões, as moradias ocupam todo o solo, e restam os espaços públicos, as escolas, as igrejas etc. para tal prática e para garantia do suprimento das necessidades de alimentos seguros e benéficos para os mais pobres. Há muitas iniciativas nesse sentido: em Catalão (GO), por exemplo, têm sido estabelecidas parcerias com escolas das redes municipal e estadual para a construção de hortas escolares/comunitárias, cuja produção é destinada à merenda escolar. A escola administra os excedentes, destinando-os aos alunos e servidores carentes. Aqui, adota-se a estratégia de desenvolver o hábito com os escolares, e estes levam as novidades/informações para suas famílias. Também foi firmada uma parceria com a Prefeitura Municipal de Catalão para apoio às iniciativas de formação de hortas urbanas e de geração de renda no distrito de Santo Antônio do Rio Verde.

Porém, em relação aos alimentos, afluem muitas variáveis, nas quais incidem as torrentes chamadas de lei da oferta e da procura, que diz respeito à elasticidade ou inelasticidade que torna a comida acessível ou inacessível conforme o estamento social do sujeito que precisa comprar seus alimentos. Nesse desafio da vida material, portanto, é presumível que quando aumentam os preços dos alimentos, a fome aumenta. $\mathrm{O}$ que poderia ser feito pelo Estado e o que poderia ser organizado pela sociedade civil? Programas e políticas de enfrentamento à fome já existem. E o que se tem certeza, por muitas experiências da história das sociedades, é que o provimento de alimentos em quantidades necessárias e com qualidade nutricional para a reprodução da vida e para a promoção da saúde humana, não deve contar apenas com a distribuição das cestas de alimentos ou dos cartões de alimentação e cartões do bolsa família, como aqueles que são mantidos pelo Ministério da Cidadania, que incorporou o antigo Ministério do Desenvolvimento Social (MDS). Mas, sobretudo, com ações que reduzam a insegurança alimentar, como, por exemplo, pela produção de alimentos em pequenos espaços nas residências urbanas e em suas áreas periféricas, ou locais públicos e vazios urbanos.

Essas ações organizadas pelos legisladores estatais são designadas de "políticas públicas". Elas são desenhadas pelos órgãos do Estado brasileiro para fazer os enfrentamentos das questões da fome, da pobreza e da insegurança alimentar e nutricional. As "políticas públicas" são de caráter permanente e ultrapassam os mandatos dos governos eleitos. São, todavia, desmobilizadas, à medida que outras intercorrências emergem ou que as razões pelas quais tenham sido criadas estejam superadas. Contudo, embora qualquer governante queira furtarse de executar as "políticas públicas", o Estado nunca deve se eximir de promover e prover o direito à alimentação adequada, com quantidade e qualidade asseguradas pelos órgãos de controle da União, estados e municípios. 
Ferreira e Castilho (2007, p. 8) afirmam que "no Brasil, em várias cidades e áreas metropolitanas, são encontradas experiências de AU [agricultura urbana] apoiadas ou não pelo Estado ou Organizações Não Governamentais (ONGs)".

A Secretaria Nacional de Segurança Alimentar e Nutricional (SESAN), vinculada ao atual Ministério da Cidadania, criou o Programa de Apoio à Agricultura Urbana e Periurbana (PAAUP). Esse programa atua com beneficiários dos programas sociais do MDS, como forma de criar alternativas para a autonomização das populações mais pobres e levá-las a ficarem independentes de projetos de assistência social capitaneados pelo Ministério da Cidadania, notadamente quanto aos aspectos da alimentação adequada. Na realidade, essa ação se embasa na criação de projetos de Agricultura Urbana e Periurbana nos municípios brasileiros, especialmente naqueles onde estão mais presentes as ações do MDS. Tais programas fundamentam-se na tentativa de promover a produção de alimentos para autoconsumo pela população urbana, notadamente aquela que se encontra em acentuada situação de pobreza, de fome e de subnutrição. Tecnicamente, são os mais vulneráveis, como também classificam os órgãos, as agências e organizações que atuam com estas populações.

Nota-se, assim como observam Machado e Machado (2002), os resultados dessas agriculturas são importantes para as famílias que as praticam, pois promovem:

[...]aumento da segurança alimentar, a melhoria da nutrição e da saúde humana nas comunidades carentes e o ambiente mais limpo, reduzindo os surtos de doenças que estão relacionados ao bem-estar da população. Em relação ao meio ambiente, destacam-se a conservação dos recursos naturais, a amenização do impacto ambiental decorrente da ocupação humana e a grande ação nas comunidades, buscando a sustentabilidade (Machado e Machado, 2002, p. 23).

Com certeza, são excelentes iniciativas para enfrentar a fome e a subnutrição. Dessa forma, a política pública pode e deve avançar mais e levar esses conhecimentos e práticas de agricultura urbana aos conjuntos urbanos nacionais.

\section{O que é a Agricultura Urbana?}

Brustolin et al. (2003) caracterizam a Agricultura Urbana contemporânea como:

[...] o tipo de agricultura que se desenvolve nos perímetros e arredores de centros urbanos de todo o mundo. Esta prática consiste na utilização que os moradores, localizados no meio urbano, fazem dos espaços domésticos e públicos para a produção de alimentos, plantas medicinais e ornamentais. As técnicas agrícolas são adaptadas à realidade urbana, como por exemplo, a utilização de recipientes plásticos para a produção de mudas e transformação de lixo orgânico em composto para a fertilização dos solos. (BRUSTOLIN et al., 2003, p. 1)

A presente conceituação da AU pelos autores configura-se pela utilização dos espaços ociosos do meio urbano, próprios, públicos ou de terceiros, que se saiba estar ocioso e baldio. Os cidadãos, por conseguinte, utilizam-se de qualquer espaço urbano que esteja acessível. É uma atividade de ocupação urbana com agricultura, na qual os prédios não ocultaram o solo cultivável. A pesquisa que se realizou em Catalão $(\mathrm{GO})$ encontrou um agricultor urbano que cultivava o solo ocioso sob a linha 
de transmissão de energia elétrica. A experiência está descrita na seção Resultados.

Entende-se, complementarmente, que a AU também se caracteriza como prática socioeconômica. Ela gera bens alimentícios naturais para a população que a desenvolve em espaços internos das cidades ou nos seus arredores. Além disso, por ter essa relação espacial com a cidade, e por servi-la, a AU configura-se como provedora da cidade e de seus moradores. Nesse mesmo escopo, Ferreira e Castilho (2007) definem a AU

[...] como sendo uma atividade social de cultivo, produção e processamento de artigos alimentícios ou não alimentícios, praticados nos espaços intra e/ou peri-urbanos; utilizando-se e disponibilizando os recursos humanos e matérias do, para e por meio do espaço urbano (FERREIRA; CASTILHO, 2007, p. 6)

É importante o destaque socioeconômico que a prática da AU tem para os citadinos e para a economia da cidade, como reconhecem esses autores. Ainda nesse mesmo itinerário, Ferreira e Castilho (2007) colocam em relevo a atividade da AU para as cidades contemporâneas ao verificarem que: "A AU tem desempenhado papel fundamental, acontecendo no espaço urbano e trazendo consigo não apenas a prática do cultivo per se, como também conjuntos de fatores sociais, econômicos e ambientais" (p. 8).

Como se observa, a $\mathrm{AU}$ voltou a se tornar uma fonte importante para a manutenção de segmentos populacionais em vulnerabilidade, fruto também da dinâmica da cidade moderna e das necessidades que a vida impõe aos citadinos. $A$ $\mathrm{AU}$, como se vem percebendo pelas pesquisas e escritos aqui referenciados, tornouse criadoura de oportunidades e de manutenção da população carente dos centros urbanos. Porém, há que se reconhecer: a AU tem recebido pouca visibilidade e tímido estímulo pelos órgãos estatais.

Por conseguinte, e diante dessa construção de conhecimentos sobre o conceito da $\mathrm{AU}$, cabe afirmar que a Agricultura Urbana é entendida como toda a prática de cultivos de alimentos, flores e animais porventura excedentes, seja para autoconsumo, seja para geração de renda familiar intentando seu sustento. Tal conceito dos autores (FERREIRA; CASTILHO, 2007) compatibiliza-se, perfeitamente, nos aportes conceituais tratados anteriormente nesta subseção.

Isso posto, resta alguma diferença conceitual significativa entre 'Agricultura Urbana' e 'Agricultura Rural'? Como afirmam Muniz et al. (2003, p. 2), a diferença entre os conceitos reside na diversidade de iniciativas na qual a Agricultura Urbana é cultivada: "a agricultura urbana pode ser praticada diretamente no solo, em canteiros suspensos, em vasos, ou em qualquer área que esteja disponível, sob luz natural ou artificial ". O que se tem definido no tipo de produto cultivado é a necessidade familiar ou mercantil, a disponibilidade de formar ambientes de cultivo e a capacidade econômica dos citadinos para formar suas hortas ou cultivos.

O fenômeno da $A U$, conclui-se, é cada vez mais comum e necessário para as populações urbanas, notadamente aquelas de menor renda e maior vulnerabilidade social. Sua presença em grandes cidades e áreas metropolitanas pode ser explicada não apenas pela densidade populacional, "mas, além da densidade populacional, existem outros fatores de expansão e diversificação da AU inerentes a 
especificidades socioespaciais de muitas cidades" (FERREIRA E CASTILHO, 2007, p. 13-14).

Sendo as necessidades e as oportunidades que induzem alguns às práticas de AU, também é importante reconhecer a sua contribuição socioambiental. Segundo as observações de Machado e Machado (2002, p. 23), as contribuições da AU ocorrem, principalmente, em "três áreas fundamentais: bem-estar, meio ambiente e economia". Nesse contexto, a AU tem se transformado em alternativa para a redução da fome e da subnutrição de segmentos das populações urbanas que as explotam. Sempre com foco no bem viver e na subsistência, a AU é, ao mesmo tempo, é ecologia e manejo de pequenos agroecossistemas.

Finalmente, Machado e Machado (2002) destacam as potencialidades, operacionalidades e impactos da $\mathrm{AU}$ ao conferirem que

\begin{abstract}
A agricultura urbana desempenha importante papel para modificar a performance ecológica das cidades e um dos maiores contrastes é a perda dos espaços nas cidades para a produção de alimentos. Entretanto, existem várias oportunidades de sanear o ambiente e a ecologia das cidades. $O$ agricultor urbano pode ajudar a criar um microclima adequado, conservar o solo, minimizar o lixo nas cidades, promover a reciclagem de nutrientes, além de melhorar o manejo da água, da biodiversidade, do balanço de $\mathrm{O} 2 \mathrm{e}$ $\mathrm{CO} 2$ e da consciência dos cidadãos urbanos (MACHADO e MACHADO, 2002, p.16).
\end{abstract}

Com toda certeza, concorda-se com as ideias dos autores citados e busca-se orientar as intervenções pedagógicas nesse mesmo sentido: cultivar e aprofundar as agriculturas dos quintais para se obter esses ganhos ambientais por meio de agriculturas com bases ecológicas, evidentemente, fundamentadas na Agroecologia.

\title{
5. O ensino da Agroecologia como base científica da AU
}

A Agroecologia, claramente, é a ciência que provê a fundamentação teórica às práticas de agricultura 'em perspectiva de sustentabilidade' (DAL SOGLIO; KUBO 2009). Isso quer dizer que as práticas de agricultura se apoiam no desenvolvimento sustentável ao longo do tempo e ao longo de gerações. Todavia quando se inicia o desenho de um agroecossistema e o plantio o que se tem é apenas uma perspectiva de, ao cabo de todo o processo, alcançar a sustentabilidade. Por conseguinte, reconhece-se que a Agroecologia é, na realidade, a teoria científica de uma prática e, assim, estabelece as conexões entre as ciências e o senso comum, além de atuar tanto na educação formal quanto na informal.

A Agroecologia é, como se diz, uma ciência que agrega e compartilha conhecimentos de muitas disciplinas, ou seja, é multidisciplinar[i], pois dialoga e constrói pontes entre as disciplinas. Contudo, a Agroecologia tem sua própria epistemologia como uma ciência que exibe complexidade, que é não convencional e que se orienta por um fazer científico em que cultura e meio ambiente coevoluem (NOGAARD, 1987). Corroborando Nogaard, Costa Gomes (2005, p. 17) afirma: a "epistemologia da Agroecologia não é a mesma epistemologia que fundamenta a ciência convencional". 
Dessa forma, ao lado de ser ciência e conhecimento, a Agroecologia também orienta, concomitantemente, um modo de fazer agricultura e atua como movimento social que tem foco humanista, pois embasa uma transformação socioambiental e econômica direcionada para o bem viver e a qualidade de vida. A Agroecologia é ciência complexa, orienta uma prática de agricultura e contém um movimento social de mudanças nas relações entre sociedade e natureza, desde a agricultura à alimentação consciente.

Nessa mesma direção, é possível afirmar que o conceito de 'agricultura em perspectiva de sustentabilidade' permeia as formas tradicionais de práticas ecológicas e de agriculturas ancestrais. Logo, as agriculturas ancestral, camponesa e tradicional têm perfis de 'agricultura em perspectivas de sustentabilidade' (DAL SOGLIO; KUBO, 2009) em todas as suas dimensões, dado que sua lógica fundante está posta na conservação e reprodução materiais, como a expressão de um desejo profundo de viver, sobreviver e reproduzir-se economicamente. Isso não exclui, em momento algum, o anseio e a necessidade da produção de excedentes que são direcionados ao mercado para a geração de ganhos socioeconômicos. $O$ fundamental, nessas operações, é não atropelar/negligenciar o ambiental para garantir os ganhos econômicos. Essas razões e conceitos estão no âmago das intervenções e formações que foram providas aos produtores, escolares e demais participantes a fim de que conheçam as bases científicas das agriculturas ecológicas.

\section{Características da Agricultura Urbana em Catalão}

Os levantamentos, nos domicílios integrantes, da amostra definida para a pesquisa e aplicação do instrumento da enquete, em 66 unidades produtoras de AU, das quais duas hortas comerciais e 64 domicílios comprovaram que a $A U$ em Catalão não é somente um hobby, mas é uma forma de obtenção de alimentos seguros, diversos e econômicos. Essa situação, também foi observada pelos pesquisadores Santandreu e Lovo (2007) ao estudar a AU na região metropolitana de Belo Horizonte:

A produção vegetal é a atividade mais frequente, estando orientada tanto ao autoconsumo (e eventualmente para troca e doação) como para a comercialização o que parece indicar que um importante número de iniciativas combina a geração de ingresso e renda como atividade principal ou complementar com a segurança alimentar e nutricional (SANTANDREU E LOVO, 2007, pp. 14-15).

$\mathrm{Na}$ pesquisa empírica que se realizou em Catalão (GO), com base nas observações de campo que os autores fizeram na região, concluiu-se que, nas hortas familiares ou comunitárias, em geral, são cultivadas hortaliças, ervas aromáticas, plantas medicinais, temperos etc., além de aves nos quintais familiares. Todos esses itens/produtos são usados para a alimentação das famílias, sendo também comum a comercialização no próprio bairro ou em feiras organizadas nos municípios. É importante considerar que esses trabalhadores não se dedicam integralmente à produção agrícola, mas apenas eventualmente, tendo outras formas de trabalho e de obtenção de receitas em suas ocupações e atividades urbanas. De certa maneira, é possível identificar que suas práticas são formas de conservação cultural e dos modos de viver herdados de seus antepassados, como também 
garantias da reprodução social, propriamente dita.

Foram visitadas 64 famílias durante a pesquisa. Destes 64 domicílios, apenas sete domicílios nada cultivavam em seus quintais. Dos 57 domicílios que praticam a $\mathrm{AU}$, foram quantificadas e separadas, por categorias, os produtos cultivados. Foram mencionadas 89 espécies cultivadas, não considerando distintas variedades. Cada domicílio tem um mix próprio de espécies, que são cultivadas em uma área média aproximada de $8 \mathrm{~m}^{2}$. As frutas, temperos e aromáticas foram as espécies mais frequentemente encontradas nos quintais, pois cerca de $90 \%$ dos domicílios (51) que mantinham práticas de AU as cultivavam.

As plantas medicinais mais comumente encontradas nos cultivos domiciliares foram: Tanssagem (Plantago major), Sete Dores (Plectranthus barbatus), Poejo (Mentha pulegium), Mastruz (Chenopodium ambrosioides), Endro (Anethum graveolens), Guaco (Mikani aglomerata), Erva Cidreira (Melissa officinalis), Erva Doce (Pipinella anisum).

Dentre as espécies frutíferas, registraram-se: Tamarindo (Tamarindus indica), Cagaita (Eugenia dysenterica), Jambroxe (Eugenia involucrata), Jabuticabeira (Myrciaria cauliflora), Jurubeba (Solanum paniculatum), Pitanga (Eugenia pitanga), Romã (Punica granatum), None (Morinda citrofilia), Mamão (Carica papaya), Mexeriqueiras (Citrus retículata), Laranjeiras (Citrus Sinensis), Limoeiros (Citrus limon) e Acerola (Malpighia glabra).

A relação de grãos, verduras e temperos inclui: Feijão Guandu (Cajanus cajan), Taioba (Xanthoso maviolaceum), Cebolinha (Allium fistulosum), Pimenta (Capsicum frutescens), Alface (Lactura sativa), Couve (Brassicas ylvestris), Salsa (Petroselinum crispum), Coentro (Coriandrum sativum), Chuchu (Sechium edule), Jiló (Solanum gilo) e Almeirão (Cichorium intybus).

$\mathrm{Na}$ categoria de criação de pequenos animais, registraram-se apenas dois domicílios que criavam aves/galinhas, para as quais reservavam $10 \mathrm{~m}^{2}$ e $25 \mathrm{~m}^{2}$ respectivamente. No gráfico 1 , podem ser conferidas as categorias e suas quantidades:

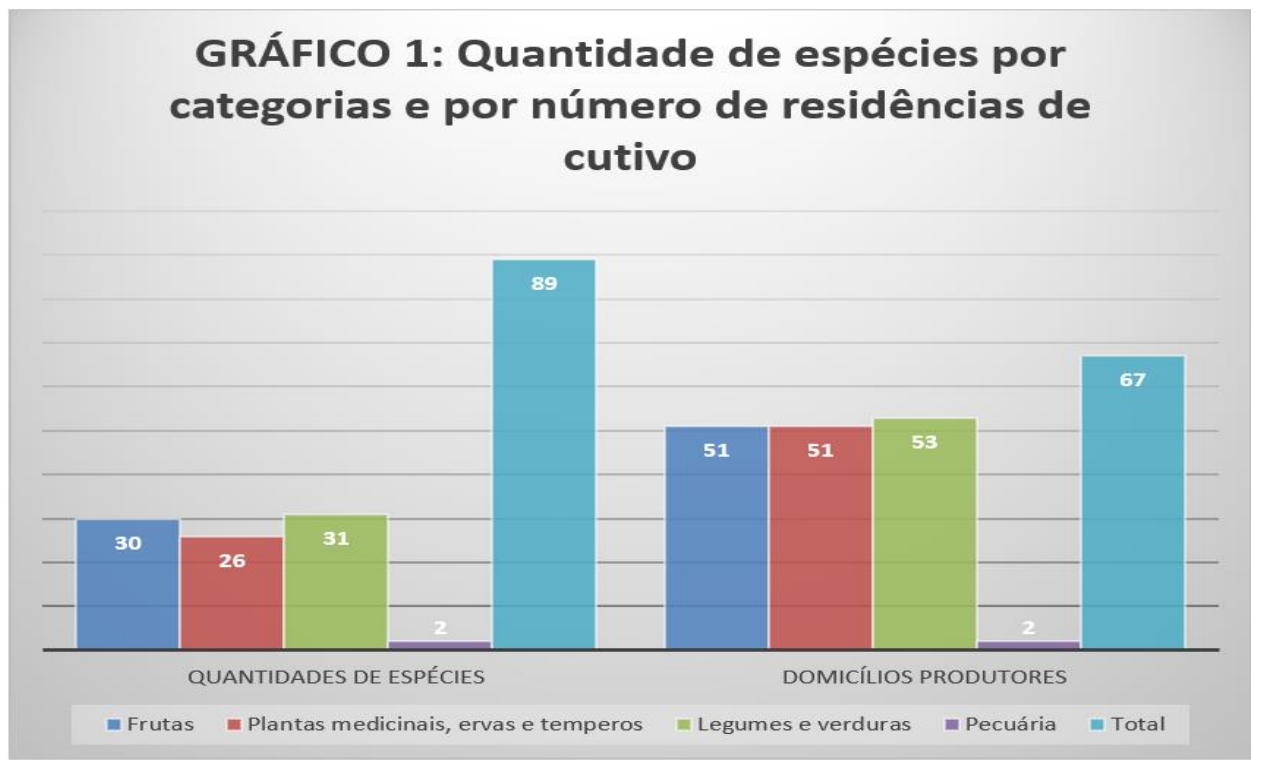

Fonte: pesquisa de campo. 
O Gráfico 1 mostra que das 89 variações encontradas, 30 eram de fruteiras; 31 , de legumes e verduras; e 26, de plantas medicinais, ervas aromáticas e temperos. Além disso, o gráfico destaca o número de domicílios em que esses cultivos estavam presentes. Também pode-se observar que foram encontradas apenas duas ocorrências de prática pecuária. As consolidações dos dados pesquisados evidenciaram que, dentre as quantidades de variedades de frutas, legumes e verduras, as plantas medicinais e ervas cultivadas alcançam quantidades são bem próximas, enquanto as quantidades de cultura pecuária são bem menores. As espécies vegetais sobrepujam as iniciativas pecuárias, fato justificado pelas políticas sanitárias praticadas nos centros urbanos.

Constatou-se, nas duas fases das enquetes, que nenhum dos domicílios utiliza agrotóxicos/venenos como medida sanitária ou profilática. As residências urbanas continuam usando apenas insumos naturais (estrumes) e biocompostos preparados no próprio quintal. Foi comum a opinião/lista de desejos dos sujeitos pesquisados de ampliarem as espécies de hortaliças e frutíferas cultivadas. Registra-se, ainda, a tônica das finalidades anteriores constatadas que é a de produzir para autoconsumo ou troca de favores com a vizinhança. Contudo, dentre todos os domicílios pesquisados, apenas um morador tinha finalidades essencialmente comerciais com sua horta. Estabelecido na Vila Cruzeiro II, esse produtor complementa sua renda com o cultivo de verduras em todo o seu lote e em lotes vizinhos que estão desocupados. Além disso, aproveita a área de passagem sob as linhas elétricas. As

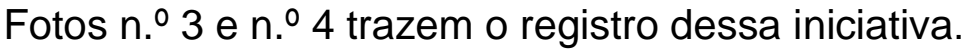

Foto 3 - Horta comercial em uma residência na Vila Cruzeiro

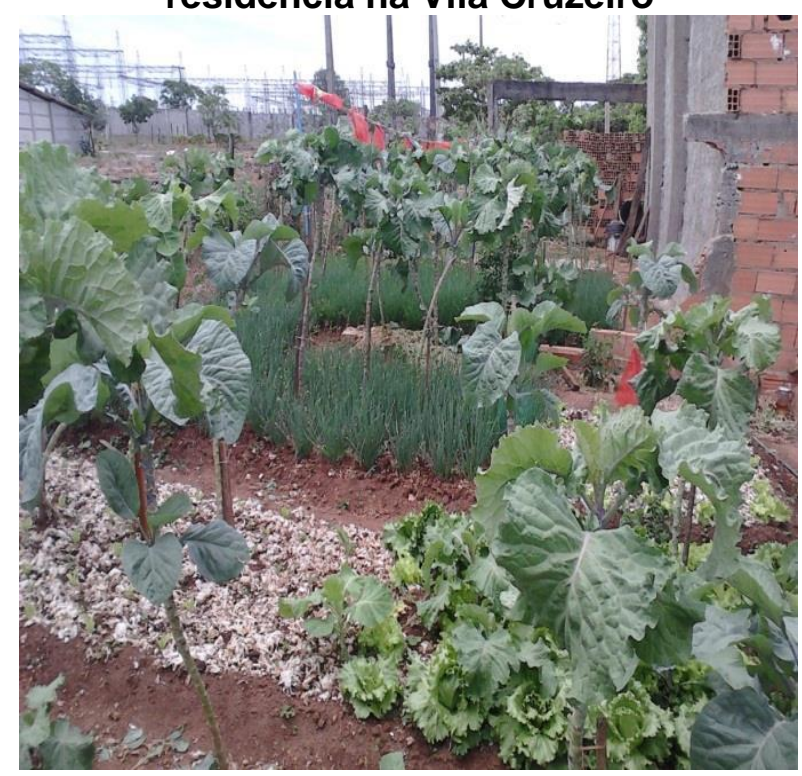

Fonte: Pesquisa de Campo 2013/2019

\section{Foto 4 - Canteiro de batata doce cultivada por debaixo dos fios de alta tensão}

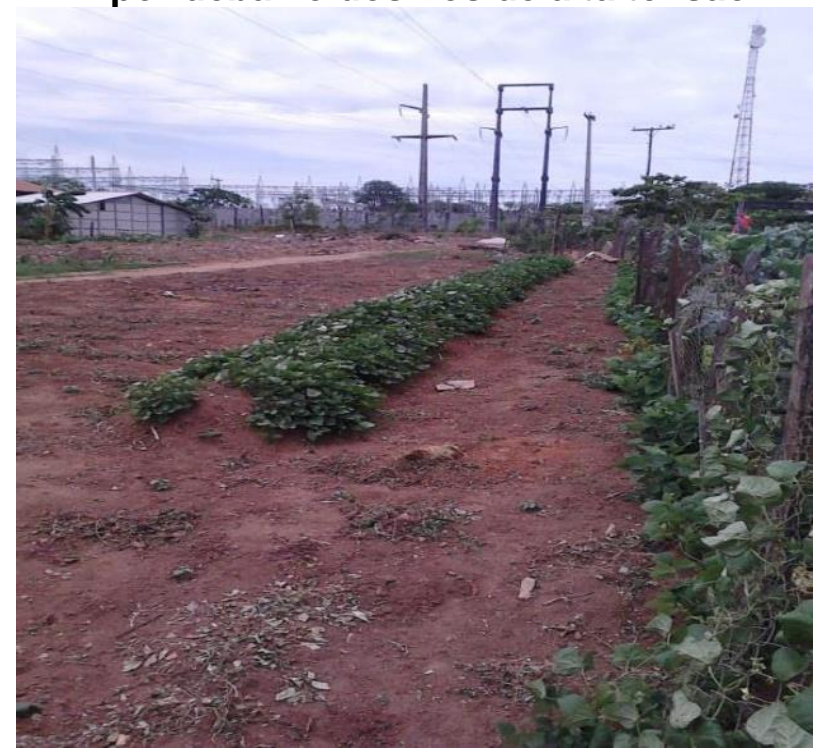

Fonte: Pesquisa de Campo 2013/2019

Em outras palavras, a tradição no fazer agrícola, é um processo social que se modifica no tempo e na prática, passando por mudanças e sofrendo seus ajustes. Entretanto, não se dilui e nem se afasta de seus princípios. Percebe-se, todavia, que há uma certa quebra no conceito de modernidade como projeto de inserção, visto 
que a tradição dos saberes aprendidos das gerações prova e falseia os novos modos de agricultura. O agricultor urbano preserva alguns dos conhecimentos tradicionais/ancestrais em suas práticas, fazendo com que a AU prescinda de ser nova ou tradicional, ancestral ou moderna: quer ser apenas ecológica e produzir 'em perspectivas de sustentabilidade', uma vez que o que está em jogo são as condições socioeconômicas. Além disso, as enquetes mostram que, em geral, não gastam com insumos para fazer e manter seus cultivos.

Dessa forma, observou-se que, comumente, os horteiros produzem seus próprios biocompostos, reciclam os nutrientes e aproveitam, após a cura natural, os estrumes dos animais que criam para alimentação ou que buscam no meio rural com proprietários de suas relações sociais. Essas práticas, são componentes do conjunto das tecnologias sociais que utilizam, em seus sistemas, agroalimentares urbanos. Enfim, os saberes, conhecimentos e experiências migram com os sujeitos quando eles migram para as cidades, e eles procuram refazer as paisagens rurais em que viveram, ainda que como uma representação social e/ou reinterpretação dessa vida rural. Tudo isso, foi observado nos 57 domicílios nos quais se encontrou alguma prática de agricultura urbana.

Verificou-se que a produção da $A U$ nesses domicílios tem sua destinação apenas para o autoconsumo. Nessas condições, essa produção está a gerar uma renda oculta, uma forma de dinheiro invisível. Nesse sentido, é preciso compreender a AU como uma fonte de renda imperceptível, mas que pode ser monetizada. Por exemplo: se uma família consumir, semanalmente, um molho de couve e um molho de cebolinha (tempero verde), o grupo terá um dispêndio médio de cerca de $R \$ 7,00$ por semana quando for comprá-lo no mercado. Considerando as 52 semanas do ano, o gasto alcança $R \$ 364,00$ apenas com esses dois produtos muito apreciados na culinária Catalana. Se tais produtos são colhidos na horta caseira, tem-se incremento nutricional sem custos para a família, e os reais não gastos podem ser direcionados para outros fins ou para poupança. Como os produtos são colhidos ao longo do ano, não se necessita de grandes espaços, e o manejo familiar proporciona a continuidade da produção.

\section{Ações de educação agroecológica com foco na agricultura urbana}

A preparação das Ações de Educação Agroecológica, que foi a última etapa das atividades do projeto sobre Agricultura Urbana em Catalão, baseou--se em ferramentas do diagnóstico participativo. As ações de formação em educação agroecológica, ao serem postas em marcha, incorporaram as proposições e experiências dos agricultores urbanos, cujas informações haviam sido coletadas na segunda etapa. Porém, ao abrir as oficinas e cursos sobre Agricultura Ecológica, ainda se fazia necessário utilizar a ferramenta do diagnóstico participativo. Essa metodologia e suas ferramentas favorecem o diálogo e a manifestação dos conhecimentos endógenos dos produtores e demais participantes dos eventos. As ações foram implementadas com a associação dos agricultores urbanos do distrito catalano de Santo Antônio do Rio Verde e da Associação de Moradores de Anhanguera e Ouvidor, municípios vizinhos de Catalão (GO), todos localizados em Goiás. As formações e os projetos de horta escolar e viveiros foram desenvolvidos em parceria com escolas desses três municípios goianos. Em Catalão (GO), realizaram-se as atividades de extensão com a formação em Agroecologia e 
construção de hortas e viveiros pedagógicos nas seguintes escolas: CAIC São Francisco de Assis, Colégio Estadual Polivalente - Dr. Tharsis de Campos - COMGO, Colégio Estadual Wilson Democh e Instituto de Educação Matilde Margon Vaz.

O diagnóstico participativo, por exemplo, proporciona corrigir algum itinerário que esteja descasado da necessidade dos participantes. No mesmo sentido, proporciona que os organizadores reprogramem/replanejem suas intervenções em funções de necessidades mais específicas dos participantes. Por meio do diagnóstico participativo, chegou-se, pontualmente, ao conhecimento das necessidades dos participantes, visto que se deu voz aos sujeitos, permitindo-se confrontar o pensamento com a experiência vivida. Como resultado, a metodologia auxiliou na definição proposições, com base nas percepções dos sujeitos e dos pesquisadores e extensionistas.

As reuniões e formações foram realizadas nas associações de bairros e nas Escolas Públicas, já citadas anteriormente, de modo que, ao longo do processo, alcançaram-se muitas residências urbanas. Aproximadamente, 50 domicílios urbanos iniciaram práticas de agricultura urbana segundo as formações das quais participaram. Isso contribuiu para que estas pudessem apropriar-se das tecnologias sociais de preparação de biofertilizantes e biocompostos, melhorar sua produtividade e avançar em direção ao estado de segurança alimentar. Em um determinado momento, centrou-se num bairro/distrito com características rurais da cidade de Catalão[i].

Essas propostas de Educação Agroecológica foram oferecidas com o objetivo de envolver os citadinos identificados com a AU com as bases científicas da Agroecologia. Elas tiveram o propósito de desenvolver competências em Agroecologia e aprendizagem de habilidades das modalidades de agricultura ecológicas. Além disso, proveram-se os agricultores e participantes de conhecimentos e aprendizagens para fazer os desenhos de agroecossistemas de forma ecológica, inspirando-se nos ecossistemas (ALTIERI e NICHOLLS, 2000).

O programa de educação agroecológica foi desenvolvido entre novembro de 2013 até dezembro de 2019 nos municípios de Anhanguera, Catalão, Cumari, Goiandira e Ouvidor. Quando não se trabalhou diretamente com os agricultores, fezse extensão nas escolas públicas do município. Utilizaram-se diversas estratégias de ensino: passando pela instrução direta, pela formação dialógica e pelo método "Horteiro a horteiro", adaptado do "Movimento Campesino a Campesino", originado na América Central (PIDAASSA, 2006). Este último fundamenta-se nos agricultores (as) e não nos oficineiros e extensionistas. A vivência do método ocorria quando os vizinhos se visitavam para pedir ajuda e explicações, uns dos outros.

Esse método tem sido sobremaneira eficaz na formação de agricultores e na implantação de práticas e tecnologias sociais apropriadas à agricultura sustentável. É visível que os agricultores possuem um vínculo de confiança que se sobrepõe aos vínculos com os técnicos, assim sentem-se mais seguros para experimentarem novas tecnologias e novas formas de fazer agricultura. Além disso, conseguem comunicar-se muito bem com seus pares, podendo colaborar na transformação da realidade. O movimento 'Campesino a Campesino' insere-se mais nos processos sociais do que propriamente nas tecnologias e na formação dos agricultores e na sua implantação (SOSA et al., 2010). 
Foram realizadas diferentes atividades, dentre elas: a) reuniões entre os participantes; b) diagnósticos rápidos participativos; c) intercâmbios; d) experimentação e demonstrações didáticas; e) visitas técnicas; e f) oficinas e cursos.

A Agroecologia e o método 'horteiro a horteiro' buscam uma revalorização dos conhecimentos ancestrais e de suas práticas, além de fornecer os princípios ecológicos para o desenho de agroecossistemas sustentáveis e resilientes (SOSA et al.; 2010). Nesse sentido, em muitos momentos, durante as formações e oficinas, foi debatido com os produtores sobre alternativas e modalidades de produções sustentáveis e sobre as possibilidades de desenhar agroecossistemas sustentáveis nos quintais dos produtores citadinos.

Ao serem promovidas ações extensionistas na direção de fomentar a Agricultura Urbana, precisou-se planejar estratégias e oficinas, nas quais foram transferidas (compartilhadas) tecnologias sociais, como por exemplo: a) produção de fertilizantes orgânicos; b) canteiros ecológicos de baixo consumo de água e situações de restrição hídrica; c) construção e demonstração de composteiras e o preparo de biocompostos para a formação de hortas e quintais agroecológicos. Todas essas ações tinham a finalidade de incrementar a quantidade e qualidade dos alimentos produzidos pelas pessoas que participaram do projeto. Outra tecnologia social que foi transferida/ensinada aos horteiros urbanos diz respeito ao manejo racional e conservacionista da água, por meio de modelos de irrigação alternativa e coleta de águas pluviais para uso nas hortas. Essas transferências de tecnologias embasaram-se nas formações e no aprender a fazer, típico da metodologia 'Horteiro a horteiro' que balizou muitas das práticas das ações extensionistas.

\section{Considerações finais}

A primeira consideração a ser feita é referente ao próprio objeto do artigo: a expectativa, quiçá a hipótese estabelecida desde a definição da amostra de domicílios, confirmou-se: há agricultores urbanos e as práticas de AU em Catalão (GO) são reais. O estudo amostral sobre a produção da $A U$, em Catalão (GO), permitiu desvelar os processos socioeconômicos dessas práticas agrícolas e identificar suas vinculações com os estilos da produção agrícola de base ecológica e com as agriculturas tradicionais. A realidade quali e quantificada proporcionou compreender e comparar a produção de alimentos nos quintais da amostra de Catalão (GO) bem como classificar/categorizar as modalidades de produção animal e vegetal nos domicílios e entender as destinações dessas produções: se seria para autoconsumo, para dádivas (trocas de vizinhança) ou para o mercado.

Considerando que a $\mathrm{AU}$ na amostra pesquisada é uma prática integradora, qualquer indivíduo ou família, que sejam independentes de seu extrato social e que possuam áreas livres e solo descoberto em suas moradas, podem cultivar alimentos e criar pequenos animais e plantas medicinais como se pôde verificar pelo fato de que há alguns citadinos que ocupam terrenos ociosos contíguos às suas residências. É fato recorrente que a AU é mais comumente presente nas moradias das classes menos abastadas, porém não é exclusiva desse estamento social. Nesses segmentos sociais, a AU está presente como uma alternativa necessária para a obtenção de alimentos e para geração de renda (ainda que não monetizada) quando se vendem (ou trocam) os excedentes. 
Tendo em vista as ações e iniciativas empreendidas desde 2013, observa-se que, até o presente momento, aconteceram avanços e retrocessos no apoio às práticas de Agricultura Urbana e ao enfrentamento à vulnerabilidade socioeconômica por parte do Poder Público e dos órgãos financiadores dos projetos de pesquisa e extensão[i]. Embora alguns programas sejam propostos pelo poder público, ainda não se logrou poder influenciar as "políticas públicas" no município que o impulsionasse na direção do envolvimento dos citadinos com a AU ou, minimamente, ver as autoridades locais fomentarem a AU em Catalão (GO).

Considera-se que o governo federal, por meio do Programa de Apoio à Agricultura Urbana e Periurbana (PAAUP) da Secretaria Nacional de Segurança Alimentar e Nutricional (SESAN), poderia capitanear ações em municípios com baixa renda e vulnerabilidade social. Porém, quando surgem iniciativas, elas apresentam um ponto de corte populacional que excluem Catalão (GO) e a sua microrregião e muitas outras cidades. Assim, os processos para criar uma cultura de AU na cidade não evoluem. Apesar desses desencontros das "políticas públicas" e programas de ações de enfrentamento à miséria e à fome, tem-se conseguido estabelecer parcerias com as escolas de Catalão (GO) e dos municípios vizinhos. Nas escolas, com a colaboração da comunidade escolar, foram implantadas hortas escolares e viveiros pedagógicos, visando estabelecer um movimento propício para o incentivo da agricultura em todo o sítio urbano no qual seja possível e lícito a sua atividade. $\mathrm{Na}$ prática, essas são iniciativas que colaboram com a conservação de espécies locais enraizadas na cultura alimentar dos moradores da cidade de Catalão (GO).

Por fim, considera-se notável que, entre os participantes da pesquisas e ações de educação agroecológica, não se perceba qualquer rejeição aos projetos de estabelecimento de hortas e formações para aprendizagem de cultivos em bases ecológicas a fim de se ter produtos seguros, nutritivos e adequados.

\section{Referências}

ALTIERI, Miguel A. NICHOLLS, Clara I. Agroecología - teoria y prática para una agricultura sustentable. México: Programa de las Naciones Unidas para el Medio Ambiente - Red de Formación Ambiental para América Latina y el Caribe, 2000.

BOLETIM Centro Ecológico - Núcleo Litoral. Soberania Alimentar e a construção de mercados locais para produtos da Agricultura Familiar. Vol. 1, Ed 1, 2008.

BRASIL. Lei no 11.346, de 15 de setembro de 2006. Cria o Sistema Nacional de Segurança Alimentar e Nutricional - SISAN com vistas em assegurar o direito humano à alimentação adequada e dá outras providências.

BRUSTOLIN, S. B. S; ISADORO, M. P; MUNIZ, T. R. P; OlIVEIRA, H. C. M, SIQUEIRA, B. L. Agricultura urbana e periurbana em Uberlândia: Um estudo de caso. In: Simpósio Regional de Geografia, 2. - 2003, Uberlândia. UFU - IGEO, 2003.

DAL SOGLIO, Fábio. KUBO, Regina Rumi. (Orgs.) Agricultura e sustentabilidade. Porto Alegre: UAB/UFRGS, 2009.

FERREIRA, Rubio José; CASTILHO, Cláudio Jorge Moura de. Agricultura urbana: discutindo algumas das suas engrenagens para debater o tema sob a ótica da 
análise espacial. Revista de Geografia. Recife: UFPE - DCG/NAPA, v. 24, no 2, mai/ago. 2007

GIL. Antonio. Como elaborar projetos de pesquisa. São Paulo: Atlas, 2009.

GOMES, João Carlos Costa. Bases epistemológicas da Agroecologia. In: AQUINO, A. M. de; ASSIS, R. L. de. (Org.). Agroecologia: Princípios e técnicas para uma agricultura orgânica sustentável. 12 ed. Brasília-DF: Embrapa Informação Tecnológica, 2005, v., p. 71-99.

MACHADO, Altair Toledo; MACHADO, Cynthia Torres de Toledo. Agricultura urbana. Planaltina (DF): EMBRAPA, 2002

MUNIZ, Thiago Ribeiro Paula et al. Agricultura urbana e periurbana em Uberlândia: um estudo de caso. In: Simpósio Regional de Geografia, 2. - 2003, Uberlândia. Universidade Federal de Uberlândia, 26-29 nov. 2003.

NOGAARD, Richard B. The Episteomology Basis of Agroecology. En Altieri Miguel. . "Agroecology. The Scientific Basis of Alternative Agriculture". Boulder: Westview Press, 1987.

Panorama da agricultura urbana e periurbana no Brasil e diretrizes políticas para sua promoção. Identificação e Caracterização de Iniciativas de AUP em Regiões Metropolitanas Brasileiras. Documento referencial geral - versão final.

PIDAASSA (Programa de Intercambio, Diálogo y Asesoría em Agricultura em Agricultura Sostenible Y Seguridad Alimentaria). Construyendo processos De Campesino a Campesino. Lima: Ed. Brot Für die Welt. 2006

Revista de agricultura urbana. Relatório de agricultura urbana no. 4. Disponível em http://www.agriculturaurbana.org.br. Acesso em 15 fev. 2012.

SANTANDREU, A. LOVO, I. C. Panorama da agricultura urbana e periurbana no Brasil e diretrizes política para sua promoção: identificação e caracterização de iniciativas de AUP em regiões metropolitanas brasileiras. Belo Horizonte: Ministério de Desenvolvimento Social e Combate à Fome, 2007. 89 p.

SOSA, B; $M$ et al. Revolución Agroecológica: El Movimiento de Campesino a Campesino de la ANAP en Cuba: Cuando el campesino ve, hace fe. Havana. Ed. ANAP. 2010 